\title{
New insight into the divergent responses of plants to warming in the context of root endophytic bacterial and fungal communities
}

\author{
Xiaoting Wei ${ }^{1}$, Fengyan Jiang ${ }^{1}$, Bing Han ${ }^{1}$, Hui Zhang ${ }^{1}$, Ding Huang ${ }^{\text {Corresp., } 1}$, Xinqing Shao ${ }^{1,2,3}$ \\ ${ }^{1}$ College of Grassland Science and Technology, China Agricultural University, Beijing, China \\ ${ }^{2}$ Key Laboratory of Restoration Ecology of Cold Area in Qinghai province, Northwest Institute of Plateau Biology, Chinese Academy of Sciences, Xining, \\ China \\ 3 Qinghai Provincial Key Laboratory of Adaptive Management on Alpine Grassland, Xining, China \\ Corresponding Author: Ding Huang \\ Email address: huangding@cau.edu.cn
}

Plant adaptation under climate changes is critical to the maintenance of terrestrial ecosystem structure and function. Studying the response of the endophytic community to climate warming is a novel way to reveal the mechanism of host environmental adaptability because of the prominent role endophytes play in host nutrient acquisition and stress tolerance. However, host performance was generally neglected in previous relevant research, which limits our understanding of the relationships between the endophytic community and host responses to climate warming. The present study selected two plants with different responses to climate warming. Elymus nutans is more suitable for growing in warm environments at low altitude compared to Kobresia pygmaea. $K$. pygmaea and $E$. nutans were sampled along an altitude gradient in the natural grassland of Qinghai-Tibet Plateau, China. Root endophytic bacterial and fungal communities were analyzed using high throughput sequencing. The results revealed that hosts growing in more suitable habitats held higher endophytic fungal diversity. Elevation and host identity significantly affected the composition of the root endophytic bacterial and fungal community. 16S rRNA functional prediction demonstrated that hosts that adapted to lower temperatures recruited endophytic communities with higher abundance of genes related to cold resistance. Hosts that were more suitable for warmer and drier environments recruited endophytes with higher abundance of genes associated with nutrient absorption and oxidation resistance. We associated changes in the endophytic community with hosts adaptability to climate warming and suggested a synchronism of endophytic communities and hosts in environmental adaptation. 
1 New insight into the divergent responses of plants to warming in the context of root

2 endophytic bacterial and fungal communities

3 Xiaoting Wei ${ }^{1}$, Fengyan Jiang ${ }^{1}$, Bing Han ${ }^{1}$, Hui Zhang ${ }^{1}$, Ding Huang ${ }^{1 *}$ and Xinqing Shao ${ }^{1,2,3}$

$4{ }^{1}$ College of Grassland Science and Technology, China Agricultural University, Beijing, China

$5 \quad{ }^{2}$ Key Laboratory of Restoration Ecology of Cold Area in Qinghai province, Northwest Institute

6 of Plateau Biology, Chinese Academy of Sciences, Xining, Qinghai Province, China

$7{ }^{3}$ Qinghai Provincial Key Laboratory of Adaptive Management on Alpine Grassland, Xining,

8 Qinghai Province, China

\section{Corresponding author:}

Ding Huang

Email address: huangding@cau.edu.cn 


\section{Abstract}

23 Plant adaptation under climate changes is critical to the maintenance of terrestrial ecosystem

24 structure and function. Studying the response of the endophytic community to climate warming

25 is a novel way to reveal the mechanism of host environmental adaptability because of the

prominent role endophytes play in host nutrient acquisition and stress tolerance. However, host performance was generally neglected in previous relevant research, which limits our understanding of the relationships between the endophytic community and host responses to climate warming. The present study selected two plants with different responses to climate warming. Elymus nutans is more suitable for growing in warm environments at low altitude compared to Kobresia pygmaea. K. pygmaea and E. nutans were sampled along an altitude gradient in the natural grassland of Qinghai-Tibet Plateau, China. Root endophytic bacterial and fungal communities were analyzed using high throughput sequencing. The results revealed that hosts growing in more suitable habitats held higher endophytic fungal diversity. Elevation and host identity significantly affected the composition of the root endophytic bacterial and fungal community. 16S rRNA functional prediction demonstrated that hosts that adapted to lower temperatures recruited endophytic communities with higher abundance of genes related to cold resistance. Hosts that were more suitable for warmer and drier environments recruited endophytes with higher abundance of genes associated with nutrient absorption and oxidation resistance. We associated changes in the endophytic community with hosts adaptability to climate warming and suggested a synchronism of endophytic communities and hosts in environmental adaptation. 
44

45

46

47

48

\section{Introduction}

Plant endophytes are microorganisms that colonize the intercellular space of plants and establish a harmonious association with their host plants (Odelade and Babalola, 2019). The genome of the host and its microbiome are considered a unit according to the hologenome theory (Zilber-Rosenberg and Rosenberg, 2008). Studies on plant-associated microbiota recently exhibited phenomenal expansion in the areas of natural and agricultural ecosystems due to their great potential in improving host fitness, including nutrient acquisition (van der Heijden, 2016), stress tolerance (Liu et al., 2020) and disease defense (Dini-Andreote, 2020; Carrión, 2019). Endophytic community diversity was closely associated with multiple ecosystem functions (Laforest-Lapointe et al., 2017).

Recently, great attention has been paid to the environmental problems caused by climate warming in terrestrial ecosystems, such as the loss of biodiversity, changes in vegetation composition and community succession. Climate changes also affect plant ranges and allow some species to expand or narrow their ranges (Morin, Viner \& Chuine, 2008). The formation of new interspecific relationships between plant species under climate change may drive these ecological processes (Little et al., 2016), and endophytes may modulate the interspecific interactions and vegetation composition (Porras-Alfaro, 2011; Jackrel, 2020).

Plant endophytic communities are dynamic and variable among seasons ( $\mathrm{Li}$, Yang \& Zhao, 2005 ) and environments (Laforest-Lapointe, 2016) and reflect the adaptability of plants to changing environments. The recent "cry for help" hypothesis suggests that plants selectively 
64

recruit beneficial microbes from their surroundings under biotic or abiotic stress (Neal et al. 2012; Liu et al. 2019). Pseudomonas colonization in the roots of the desert plant Alhagi sparsifolia increased under drought conditions and promoted drought resistance (Zhang et al., 2020). Different plant species show unique abilities in the process of recruitment. For example, most plants form symbioses with arbuscular mycorrhizal fungi (AMF) to increase phosphorus availability. Arabidopsis thalian, which lose the ability of symbiosing with AMF, recruit Helotiales and Colletotrichum tofieldiae under phosphorus-limited conditions (Almario et al., 2017; Hiruma et al., 2016).

However, studies on the impacts of climate change on plant endophyte communities are insufficient and many findings are conflicting. Endophytes and their hosts are "communities of interest". Previous studies focused only on endophytic communities and host responses to climate change were generally neglected (Qian et al., 2018; Cordier et al., 2012), which limits our understanding of the ecological significance of endophytic community changes. Host selection is critical because plant species (Yao et al., 2019; Laforest-Lapointe, Messier \& Kembel, 2016) and compartments (leaf, stem, root) of the same plant greatly affect endophytic community composition (Qian et al., 2019). Fujimura also concluded that the conflicting results between studies on the effects of warming on endophytic communities may due to differences in host responses (Fujimura, Egger \& Henry, 2008). Therefore, plant species that are sensitive to climate changes should be selected to examine the responses of endophyte communities and improve our understanding of plant-microbe interactions and elucidate the mechanisms of plant adaptation to climate change from the perspective of endophytes. 
The Qinghai-Tibet Plateau is the highest plateau in the word, and it is experiencing rapid

86

87

climate warming at rate more than twice the global level (Ma et al., 2017), which threatens

biodiversity and ecosystem function in this area. Kobresia pygmaea and Elymus nutans are two common plants in the Qinghai-Tibet Plateau that respond differently to climate warming. Kobresia pygmaea is a carpet-like sedge species that is highly adaptable to high-altitude environments, and it primarily grows on the alpine meadow of the Qinghai-Tibet Plateau between altitudes of $3000 \mathrm{~m}$ and $6000 \mathrm{~m}$ (Wu et al., 2017; Miehe et al., 2008). The K. pygmaea alpine meadow, which is dominated by K. pygmaea, covers $17 \%$ of the total area of the QinghaiTibet Plateau (Miehe et al., 2008), which makes it an important species in maintaining the stability of the local ecosystem. Elymus nutans is a dominant and constructive grass of meadow steppe, and it is characterized by strong drought, cold and pest resistance. It is widely distributed and survives at elevations ranging from $450 \mathrm{~m}$ to $4500 \mathrm{~m}$. E. nutans is better suited to low altitudes and warmer habitats than K. pygmaea, and an increase in temperature from high to low elevations promotes the growth of E. nutans (Qi et al., 2020). K. pygmaea primarily grows at high altitudes in humid and cold habitats (Wu et al., 2017). Warming increased the proportion of Elymus nutans and decreased the proportion of K. pygmaea in alpine grassland ecosystems (Liu et al., 2018; Niu et al., 2019).

The present study examined the adaptability of plants to climate warming by analyzing changes in endophytic community diversity and composition. We used elevation gradients where climatic conditions, vegetation and soil characteristics show regular changes over short geographic distances to investigate the responses of terrestrial ecosystems to climate warming 
106 (Korner, 2007). K. pygmaea and E. nutans were sampled along an elevation gradient in the 107 Qinghai-Tibet Plateau, and the root endophytic bacterial and fungal communities were analyzed

108

109

110

111

112

113

114

115

116

117

118

119

120

121

122

123

124

125

126

based on the high-throughput sequencing. The innovation of this study lies in the selection of the two hosts with opposing responses to climate warming to elucidate how endophytic communities change during the promotion or inhibition of host growth by climate warming. We addressed the following questions: 1) how endophytic community diversity in the roots of $K$. pygmaea and $E$. nutans changed with climate warming (decreasing elevation); 2) whether climate warming affected endophytic community composition in K. pygmaea and E. nutans; and 3) how changes in the endophytic community explain host responses to climate warming.

\section{Materials and Methods}

\section{Study site and sampling}

Fieldwork was performed in August 2019 in the middle of the Qilian Mountains $\left(37.68^{\circ} \mathrm{N}\right.$, $\left.100.75^{\circ} \mathrm{E}\right)$ near Qilian County, which is located in the northeastern part of Qinghai Province, China. With an average elevation over $3000 \mathrm{~m}$, this area experiences a typical plateau continental climate. The mean annual and growing season temperatures (from June to August) are $1{ }^{\circ} \mathrm{C}$ and $13^{\circ} \mathrm{C}$, respectively. The annual mean precipitation is $480 \mathrm{~mm}$, with $80 \%$ occurring during the growing season. The climate and vegetation composition change significantly with elevation in the Qilian Mountains. We sampled at elevations of 3350 m, 3460 m, 3570 m, 3 $680 \mathrm{~m}$, and $3800 \mathrm{~m}$ above sea level (a.s.1.) on the south slope of the mountain. The temperature decreases and the precipitation increases with increasing altitude in this area (Jin et al., 2017; Li et al., 2018). According to the vegetation investigation, the grassland was classified as alpine 
127

128

129

130

131

132

133

134

135

136

137

138

139

140

141

142

143

144

145

146

147

meadows at elevations of $3350 \mathrm{~m}, 3460 \mathrm{~m}$, and $3570 \mathrm{~m}$ and alpine shrub meadows at

elevations of $3680 \mathrm{~m}$ and $3800 \mathrm{~m}$.

We defined three plots at each elevation, with each plot $20 \mathrm{~m}$ away from the other plots. The roots of K. pygmaea and E. nutans were sampled around each plot. K. pygmaea always

aggregates in grasslands and forms slightly yellow green patches because of its dense network of roots, which are produced clonally. Therefore, patches of K. pygmaea and clumps of E. nutans were dug using a sterilized shovel from a depth of $10 \mathrm{~cm}$. We reserved the belowground parts, including the soil and roots, when sampling, and separated the roots after transported to the laboratory. We reserved the belowground parts, including the soil and roots, when sampling, and separated the roots after transport to the laboratory. Five individuals of each plant species per plot composed one sample, which resulted in 30 root samples $(2$ species $\times 5$ elevations $\times 3$ replicates). All samples were placed in labeled sterile plastic bags and immediately stored in an incubator with dry ice. Samples were transported to the laboratory and stored at $-80^{\circ} \mathrm{C}$ until further processing. The roots of K. pygmaea and E. nutans were separated in the laboratory using sterilized scissors and brushes then transferred to $50-\mathrm{mL}$ sterile centrifuge tubes containing 30 $\mathrm{mL}$ of $0.01 \mathrm{M}$ sterilized PBS $\left(136 \mathrm{mM} \mathrm{NaCl}, 8 \mathrm{mM} \mathrm{Na}_{2} \mathrm{HPO}_{4}, 2 \mathrm{mM} \mathrm{KH}_{2} \mathrm{PO}_{4}, 2.6 \mathrm{mM} \mathrm{KCl}, \mathrm{pH}\right.$ 7.2). The tubes were placed on a shaking platform $(180 \mathrm{rpm})$ for $20 \mathrm{~min}$ to remove the soil attached to the root. The roots were rinsed in deionized water and surface sterilized according to the following steps: immersion in sterile water twice for $30 \mathrm{~s}$, $75 \%$ ethanol for $1 \mathrm{~min}, 3.25 \%$ sodium hypochlorite for $3 \mathrm{~min}, 75 \%$ ethanol for $30 \mathrm{~s}$, sterile water for $1 \mathrm{~min}$, and a final rinse with sterile water. The surface-sterilized roots were stored in a freezer at $-80^{\circ} \mathrm{C}$. 
148

149

150

151

152

153

154

155

156

157

158

159

160

161

162

163

164

165

166

167

168

\section{Genomic DNA extraction, amplification and purification}

Endophytic genomic DNA was extracted from $0.5 \mathrm{~g}$ of frozen surface-sterilized roots using the MOBIO PowerSoil ${ }^{\circledR}$ DNA Isolation Kit (MOBIO Laboratories, Carlsbad, CA, USA). The integrity and purity of the extracted DNA were tested on $1 \%$ agarose gels, and a NanoDrop One was used to measure the concentration and purity of the extracted DNA. The 16S rRNA gene V5-V7 region was amplified using the primers 799F (5'-AACMGGATTAGATACCCKG-3') and 1193R (5'-ACGTCATCCCCACCTTCC-3') with a 12-bp barcode (Horton et al., 2014). The primer set 799F-1193R reduces co-amplification levels of mitochondrial gene during endophytic 16S rRNA gene PCR amplification (Wang et al., 2018). The internal transcribed spacer 1(ITS1) region of fungal rRNA was amplified using the forward primer 5'-

CTTGGTCATTTAGAGGAAGTAA-3' and the reverse primer 5'GCTGCGTTCTTCATCGATGC-3' (Horton et al., 2014). Primers were constructed by Invitrogen (Carlsbad, CA, USA). A $50-\mu \mathrm{L}$ reaction containing $25 \mu \mathrm{L}$ of $2 \mathrm{x}$ PremixTaq (Takara Biotechnology, Dalian Co. Ltd., China), $1 \mu \mathrm{L}$ of each primer $(10 \mathrm{mM})$ and $3 \mu \mathrm{L}$ of DNA template $(20 \mathrm{ng} / \mu \mathrm{L})$ was used for PCR amplification in a BioRad S1000 (Bio-Rad Laboratory,

CA). The following thermal cycling process was used: $5 \mathrm{~min}$ at $94^{\circ} \mathrm{C}$ for initialization; 30 cycles of denaturation at $94^{\circ} \mathrm{C}$ for $30 \mathrm{~s}$; annealing at $52^{\circ} \mathrm{C}$ for $30 \mathrm{~s}$; extension at $72^{\circ} \mathrm{C}$ for $30 \mathrm{~s}$; and final elongation at $72^{\circ} \mathrm{C}$ for $10 \mathrm{~min}$. The PCR products of 3 replicates of each sample were mixed, and $1 \%$ agarose gel electrophoresis was used to detect the quality of the PCR products. The products were mixed in equidensity ratios according to GeneTools analysis software (version 4.03.05.0, SynGene). An EZNA Gel Extraction Kit (Omega, USA) was used for purification of the mixed 
169

170

171

172

173

174

175

176

177

178

179

180

181

182

183

184

185

186

187

188

189

PCR products.

\section{Library preparation and sequencing}

Libraries were processed with the NEBNext ${ }^{\circledR}$ Ultra $^{\mathrm{TM}}$ DNA Library Prep Kit for Illumina ${ }^{\circledR}$

(New England Biolabs, USA). The libraries were assessed using a Qubit@2.0 fluorometer

(Thermo Scientific) and an Agilent Bioanalyzer 2100 system, and sequenced on the Illumina

HiSeq 2500 platform to generate 250-bp paired-end reads. High-quality clean reads were

obtained following the Trimmomatic quality control process (V0.33,

http://www.usadellab.org/cms/?page=trimmomatic). The clean paired-end reads from which the

barcodes and primers were removed, were merged using FLASH (V1.2.11,

https://ccb.jhu.edu/software/FLASH/). Effective clean tags were retained after filtering the spliced sequences using Trimmomatic software.

\section{OTU cluster and species annotation}

Usearch software (V8.0.1517, http:/www.drive5.com/usearch/) was applied for sequence

analysis. Sequences with $\geq 97 \%$ similarity were assigned to the same operational taxonomic unit

(OTU). Singletons were removed using usearch

(http://www.drive5.com/usearch/manual/chimera_formation.html) after OTU clustering, and the

chimera sequences were detected and removed using the UCHIME de novo algorithm

(http://www.drive5.com/usearch/manual/uchime_algo.html). The Greengenes

(http://greengenes.secondgenome.com/) and UNITE V8.0 databases were consulted based on the

RDP Classifier algorithm and the assign_taxonomy.py script

(http://qiime.org/scripts/assign_taxonomy.html) in QIIME for taxonomic annotation (the 
190

191 (16S rRNA) and could not be annotated at the kingdom level were removed.

confidence threshold was set to 0.8 ). OTUs that were annotated as chloroplasts or mitochondria

192

193

194

195

196

197

198

199

200

201

202

203

204

205

206

207

208

209

210

\section{Data analysis}

The Shannon index of the endophytic bacterial and fungal communities was calculated using QIIME (V1.9.1), and the Kruskal-Wallis test at the $P<0.05$ level was used to examine the effects of elevation and species on the diversity of endophytic bacterial and fungal community.

Nonmetric multidimensional scaling (NMDS) analysis based on Bray-Curtis distance was performed to visualize the dissimilarities of endophytic bacterial and fungal community composition in different species and at different elevations. Permutational multivariate analysis of variance (PerMANOVA) using the "Anosim" function in R (3.6.1) with 999 random permutations was performed to compare differences in endophytic community structure between plant species and elevations. The correlations of elevation and the relative abundances of the top 20 genera were analyzed using the Spearman method. Samples from different elevations were combined for further analysis of the differences in endophytic bacterial and fungal communities between the two plant species. The linear discriminant analysis (LDA) effect size (LEfSe) method with a threshold of 4 was used to investigate indicator species that exhibited significant differences in relative abundance between plant species. KEGG functional analysis of endophytic bacteria was performed using Phylogenetic Investigation of Communities by Reconstruction of Unobserved States (PICRUSt) (Langille et al., 2013). We also analyzed genes associated with cold resistance, antioxidant enzymes (catalase, peroxidase and superoxide dismutase), nitrogen metabolism (nitrogen fixation, nodulation protein, nitrogen regulatory 
211 protein, and nitrate reductase) and phosphorus metabolism (phosphatase). $\mathrm{Ca}^{2+}$ signaling

212 (Monroy, Sarhan \& Dhindsa, 1993), cold shock proteins, HSP20 family proteins (Elkelish et al.,

213 2020), glutathione (Liu et al., 2020), glycerol-3-phosphate acyltransferases (Gomes et al., 2000),

214 glycine betaine (Annunziata et al., 2019; Chen and Murata, 2011), glycosyltransferases (Shi et

215 al., 2020), protein kinases (histidine kinase, serine protein kinase, and tyrosine kinase) (Martín

216 and Busconi, 2001), trehalose (Liu et al., 2020), nitric oxide (Farnese et al., 2016), and

217 antioxidant enzymes (Baier et al., 2019) have been reported to improve plant cold resistance.

218 Results

219 Diversity of endophytic bacterial and fungal communities

220 The rarefaction curves of the Shannon index reached a saturation plateau in all samples,

221 which suggested that the sampling was sufficient to obtain most of the OTUs (Fig. S1). We

222 found a higher Shannon index of the root endophytic bacterial and fungal communities in $K$.

223 pygmaea than E. nutans. Elevation significantly affected the Shannon index of root endophytic

224 bacteria in K. pygmaea, but not E. nutansby (Fig. 1A). The Kruskal-Wallis test revealed that

225 elevation had a significant effect on the Shannon index of root endophytic fungi in E. nutans $(P$

$226=0.021)$ but not K. pygmaea $(P>0.05)$. The Shannon index of endophytic fungi in E. nutans

227 roots decreased significantly with increasing altitude, but an inconspicuous increasing trend was

228 observed for K. pygmaea roots (Fig. 1B). There was no significant difference in the Shannon

229 index of root endophytic fungi between K. pygmaea and E. nutans at lower elevations (3 350-3

$230570 \mathrm{~m}$ ). The Shannon index of root endophytic fungi was much higher in $K$. pygmaea than $E$.

231 nutans at higher elevations (3 680 and $3800 \mathrm{~m}$ ).

Peer] reviewing PDF | (2020:12:56554:2:0:NEW 1 Apr 2021) 


\section{Community compositions of endophytic bacteria and fungi}

The NMDS ordination (Fig. 2) and analysis of similarities (ANOSIM) (Table 1) showed

234

235

236

237

238

239

240

241

242

243

244

245

246

247

248

249

250

251

252

that endophytic bacterial and fungal community composition in K. pygmaea was significantly different than $E$. nutans $(R=0.78, P=0.001 ; R=0.58, P=0.001)$ (Fig. 2A, 2B). Elevation also obviously influenced root endophytic bacterial and fungal communities in $E$. nutans $(R=0.42$, $P=0.001 ; R=0.84, P=0.001)($ Fig. $2 \mathrm{C}, 2 \mathrm{D})$ and $K$. pygmaea $(R=0.76, P=0.001 ; R=0.98, P=0.001)$

(Fig. 2E, 2F). The root endophytic bacterial community composition in K. pygmaea was more sensitive to elevation than E. nutans, which was validated by the R value of ANOSIM (Table 1). Greater the $\mathrm{R}$ values indicate a more significant influence of altitude on community composition.

The endophytic fungal community was more sensitive to elevation than the bacterial community for each species. Plant identity had a greater influence on the endophytic bacterial community than the fungal community.

Proteobacteria was the predominant phylum in E. nutans and $K$. pygmaea roots (Fig. S2A).

The average relative abundance of Proteobacteria was 58\% in K. pygmaea roots, which was much lower than E. nutans $(80 \%)$. Actinobacteria was the subdominant phylum in K. pygmaea roots and accounted for $30 \%$ of the bacterial reads, which was much higher than its abundance in E. nutans roots $(1.4 \%)$. There were significant differences in root endophytic bacterial community composition at the order level between $K$. pygmaea and E. nutans (Fig. 3A). For E. nutans roots, Pseudomonadales was the most abundant order, with the relative abundance ranging from $36 \%$ to $69 \%$ along the elevation gradient. The endophytic bacterial community composition was more uniform in K. pygmaea roots than E. nutans roots. Rhizobiales accounted 
253 for $20 \%$ of the total community abundance, and there was no obvious difference between

254 elevations. Pseudomonadales was highly abundant (50\%) at the elevation of $3800 \mathrm{~m}$, and

255 Pseudonocardiales showed low abundance at this elevation.

256 Most endophytic fungi in all samples belonged to ascomycetes, with average $76 \%$ for $E$.

257 nutans roots and 61\% for K. pygmaea (Fig. S2B). Helotiales were the dominant order in $E$.

258 nutans roots and were more abundant at high altitudes, which was different from that in $K$.

259 pygmaea (Fig. 3B). Pleosporales were more abundant in K. pygmaea roots than E. nutans roots,

260 especially at lower altitudes (3 350-3 $570 \mathrm{~m}$ ). Agaricales were enriched in K. pygmaea roots at

261 higher altitudes (3 $680 \mathrm{~m}$ and $3800 \mathrm{~m}$ ) and more abundant in E. nutans roots (Fig. 3B). The

262 relative abundance of Hypocreales in K. pygmaea roots were $18.55 \%$ and $8.1 \%$ at $3350 \mathrm{~m}$ and 3

$263460 \mathrm{~m}$, respectively, which was higher than E. nutans roots at the same elevations (Fig. 3B).

264 We compared the abundances of the top 20 OTUs which covered more than $50 \%$ of the total reads in all samples at different altitudes and found that plants tended to be enriched with specific endophytes at different elevations (Fig. S3A-D). Species with significant differences in relative abundance between $K$. pygmaea and E. nutans were analyzed according to LEfSe (Fig.

4). The results indicated that bacterial species belonging to Actinobacteria (Frankiales,

Pseudonocardiales and Micromonosporales) and Rhizobiales (Rhizobiaceae) were highly

(Pseudomonadaceae) and Flavobacteriales (Flavobacteriaceae) were highly enriched in E. nutans roots (Fig. 4A). Fungal species belonging to Dothideomycetes (Pleosporales), Eurotiomycetes 
274 K. pygmaea roots, and Helotiales (Hyaloscyphaceae, Helotiaceae) and Tremellales

275 (Bulleribasidiaceae) were highly enriched in E. nutans roots (Fig. 4B).

The correlations of the relative abundances of the top 20 genera and elevation were

277

analyzed (Table 2). For bacterial communities, the relative abundances of Pantoea,

Sphingomonas, and Paenibacillus in E. nutans roots showed positive correlations with elevation.

The relative abundances of Pseudomonas, Pantoea, Serratia, and Paenibacillus in K. pygmaea roots positively correlated with elevation, and Rhizobium, Acidibacter, Actinophytocola, and Cryptosporangium negatively correlated with elevation. For fungal communities, the relative abundances of Mortierella and Cistella showed negative correlations with elevation in E. nutans roots. The relative abundances of Mycena, Mortierella, Ilyonectria, Sebacina, and Leptosphaeria showed positive correlations with elevation in $K$. pygmaea roots.

$$
\text { The results of 16S rRNA functional prediction indicated that the endophytic bacterial }
$$

community in E. nutans roots had a higher abundance of genes associated with nitrogen fixation, phosphatase activity and antioxidase activity and a lower abundance of genes associated with cold resistance than K. pygmaea roots (Fig. 5). Genes associated with nutrient absorption, including nitrogen fixation, nodulation, and phosphatase activity, were enriched in K. pygmaea roots at higher elevations. These genes were enriched at lower elevations in E. nutans roots, (Fig. S4).

\section{Discussion}

\section{Diversity of the endophytic community along an elevation gradient}

Most studies on the influence of climate change on plant associated microbial communities 
295

296

297

298

299

300

301

302

303

304

305

306

307

308

309

310

311

312

313

314

315

overlooked host responses and did not link the responses of hosts and endophytes (Qian et al.,

2018; Cordier et al., 2012). Therefore, the significance of changes in the endophytic community

of the host in response to climate change were not well explained. Two plant species showing

contrasting responses to climate warming were selected in the present study to fill in this

knowledge gap. The increase in endophytic fungal diversity in E. nutans and decrease in $K$.

pygmaea with warming (i.e., decreasing elevation) indicated that the endophytic fungal diversity

of plants growing in suitable environments was higher than plants growing in unsuitable habitats.

Our findings demonstrated that changes in endophytic fungal diversity under climate warming

were closely related to host adaption, and endophytic diversity decreased when the climate

became unfavorable for plant growth. A previous study indicated that endophytic diversity in

sugar maple seedlings was higher within its natural range than at the edge of species' elevational

range (Wallace, Laforest-Lapointe \& Kembel, 2018), which was consistent with the results of our

study. We hypothesized that the loss of endophytic diversity in adverse environments was related

to host selection. The symbiotic relationships between the host and some endophytes break down,

and some endophytes that are beneficial to host survival are selectively enriched (Werner et al.,

2018).

Plant adaptability to environmental changes is very complex and affected by many factors.

We just found a phenomenon that fungal diversity was higher in the habitat that suitable for host

growth. However, no direct cause-and-effect relationship between fungal diversity and host

adaptation was demonstrated in the present study. Whether higher endophytic diversity

contributes to host growth is worthy to study in the future.

Peer] reviewing PDF | (2020:12:56554:2:0:NEW 1 Apr 2021) 
316

317

318

319

320

321

322

323

324

325

326

327

328

329

330

331

332

333

334

335

336

\section{Species and elevation significantly affected the root endophytic bacterial and fungal}

communities

Previous studies indicated that plant endophytes showed significant host preferences (Toju,

Kurokawa \& Kenta, 2019; Yao et al., 2019). Different plant species sharing similar environments recruit different microbial communities in roots (Aleklett et al., 2015), which may be related to the metabolic characteristics of the host. Because root exudates contain important factors that shape endophytic microbiome assembly, such as salicylic acid (Lebeis et al., 2015) and jasmonic acid (Carvalhais et al., 2015). Environmental parameters are also key factors thatcause changes in the endophytic community (Carper et al., 2018; Bei et al., 2019; Chen et al., 2019). Climate characteristics, soil nutrients and vegetation composition change along altitude gradients, which may cause variations in the endophytic community (Cai et al., 2020; Zarraonaindia et al., 2015). Plant species and altitude significantly affected the root endophytic bacterial and fungal community composition in the present study. The bacterial community composition was affected more strongly by plant species, and elevation more strongly affected the fungal community.

Previous studies also concluded that fungal communities were more susceptible to geographic distance than bacterial communities (Coleman-Derr et al., 2016; Meiser, Bálint \& Schmitt, 2014).

Among the endophytic bacteria, Proteobacteria was the predominant phylum in E. nutans and K. pygmaea roots, which was consistent with many other studies involving different plant species (Bulgarelli et al., 2012; Beckers et al., 2017; Carrell and Frank, 2015). However, K. pygmaea roots had a higher abundance of Actinobacteria than E. nutans roots. At the order level, the relative abundances of Pseudonocardiales, Frankiales and Rhizobiales in K. pygmaea roots 
337 were much higher than E. nutans roots. However, E. nutans roots had a higher abundance of

338 Pseudomonadales. These root endophytes promote host plant growth and help plants resist biotic

339 and abiotic stress (Hasegawa, et al., 2006; Santoyo et al., 2016). Pseudomonas participates in

340 nitrogen fixation (Yan et al., 2008) and iodoacetamide (IAA) synthesis (Taghavi et al., 2009),

341 which promote plant growth. In addition to symbiosis with leguminous plants, Rhizobium acts as

342 an endophyte of nonleguminous plants to promote nitrogen and phosphorus uptake and improve

343 the photosynthetic rate (Yanni et al., 2001; Chi, 2006). Helotiales, which promote phosphorus

344 absorption in nonmycorrhizal plants (Almario et al., 2017), were enriched in E. nutans roots.

345 Some genera, such as Mortierella, showed positive correlations with elevation in K. pygmaea but

346 negative correlations with elevation in E. nutans, which also reflected the plant selectivity.

347 Functional differences of root endophytic bacteria in $K$. pygmaea and E. nutans

348 Chilling stress is an important environmental factor that affects plant growth and

349 geographical distribution (Lv et al., 2018), which is especially true on the Qinghai-Tibet Plateau.

350 A previous study also demonstrated that temperature and altitude factors primarily affected the

351 distribution of alpine meadow grass (Lu et al., 2020). Symbiosis with bacteria that could improve

352 the cold tolerance of the host represents a survival strategy in alpine regions with high elevations

353 (Acuna-Rodriguez et al., 2020; Tiryaki, Aydin \& Atici, 2019). Beirinckx et al. also indicated that

354 the root microbiome promoted maize growth under chilling conditions (Beirinckx et al., 2020).

355 The present study provided new insight into the role of endophytic bacteria in host adaptation to

356 climate warming in terms of bacterial functional genes associated with cold resistance and

357 nutrient absorption.

Peer) reviewing PDF | (2020:12:56554:2:0:NEW 1 Apr 2021) 
The study area in the present study exhibited a cold and wet climate at high altitudes and a

359

360

361

362

363

364 warm and dry climate at low altitudes. Temperature is the main factor affecting plant growth at high elevations. Increased recruitment of bacteria with cold resistance ability in K. pygmaea roots made this plant more adaptable to high altitude than E. nutans although the abundance of genes associated with nutrient uptake was higher in E. nutans than K. pygmaea. Because the expression of these genes and the enzymes activity involved in nutrient absorption are restricted by low temperatures. Therefore, symbiosis with high abundance of these endophytes in E. nutans cost plant carbohydrates without getting the expected return.

The outcomes of symbiosis with microbiomes are environmentally dependent (Rubin et al., 2020). For example, arbuscular mycorrhizal fungi significantly enhance phosphorus absorption and promote plant growth in phosphorus deficient soils, but the contribution of mycorrhizal pathways to phosphorus uptake in plants is weakened under high P soil condition (Chu et al., 2020). Climate warming relieves cold stress at high elevations and exacerbates heat and drought stress at lower elevations (Reinhardt et al., 2011; Moyes et al., 2013). With climate warming or decreasing altitude, plant growth is freed from the cold limitation. Selectively symbiosis with bacteria that have the ability to facilitate host nutrient absorption, such as nitrogen fixation and phosphorus solubilization, in E. nutans roots made this plant more adaptable to warming environments than K. pygmaea.

Endophytes do not always establish harmonious symbioses with plant hosts. They also cause host disease and other adverse effects. There in a 'balance of antagonisms' relationship between fungal and plant partners (Schulz and Boyle 2005). We only focused on the "good" side of

Peer] reviewing PDF | (2020:12:56554:2:0:NEW 1 Apr 2021) 
379

endophytes for their importance in maintaining a stable symbiotic relationship. Exploring beneficial roles of endophytes to their hosts in special environments such as the Qinghai-Tibet Plateau contributes a lot to the development and application of microbial resources. However, functional prediction alone is not sufficient to directly demonstrate the role of endophytic bacteria in host responses to climate changes. Further studies should concentrate more on the interactions between endophytic community and host to rich our understanding of responses of terrestrial ecosystem to global warming.

\section{Conclusions}

The present study demonstrated that the diversity of the endophytic community was higher in hosts growing in habitats that were conducive to its growth. K. pygmaea, with higher endophytic diversity and greater abundance of genes associated with cold resistance, was suited for growth in cold areas at high altitudes, and its growth was suppressed by warming. Higher endophytic diversity and greater abundance of genes associated with nutrient absorption and oxidation resistance in warmer environments (lower altitude) may contribute to the growth of $E$. nutans under global warming (Fig. 6). We also found that the relative abundances of the same taxa in different hosts showed different correlations with elevation, which demonstrated that the ability to recruit endophytes differed between the hosts when the habitat changed. Our study highlights the importance of plant endophytes in the responses of terrestrial ecosystems to 
400 climate change.

401 Acknowledgements

402 We would like to thank $\mathrm{Lu} \mathrm{Yu}$, Wan-tong Zhang for their contribution to the filed sampling;

403 Chang-lin $\mathrm{Xu}$ for his help in plant species identification.

404 Conflict of interest:

405 The authors declare there are no competing interests

406

407

408

409

410

411

References

412

Acuna-Rodriguez IS, Newsham KK, Gundel PE, Torres-Diaz C, Molina-Montenegro MA. 2020. Functional roles of microbial symbionts in plant cold tolerance. Ecology Letters 23: 1034-1048.

Aleklett K, Leff JW, Fierer N, Hart M. 2015. Wild plant species growing closely connected in a subalpine meadow host distinct root-associated bacterial community. Peer J. 3: e804.

Almario J, Jeena G, Wunder J, Langen G, Zuccaro A, Coupland G, Bucher M. 2017. Rootassociated fungal microbiota of nonmycorrhizal Arabis alpina and its contribution to plant phosphorus nutrition. PNAS 114: 9403-9412. 
421

422

423

424

425

426

427

428

429

430

431

432

433

434

435

436

437

438

439

440

441

temporal profile of glycine betaine accumulation in plants under abiotic stresses. Frontiers in Plant Science. 10: 230.

Baier M, Bittner A, Prescher A, van Buer J. 2019. Preparing plants for improved cold tolerance by priming. Plant Cell Environment. 42: 782-800.

Beckers B, Beeck MOD, Weyens N, Boerjan W, Vangronsveld J. 2017. Structural variability and niche differentiation in the rhizosphere and endosphere bacterial microbiome of fieldgrown poplar trees. Microbiome 5: 25.

Bei Q, Gerald M, Wu XH, Christoph M, Werner L. 2019. Metatranscriptomics reveals climate change effects on the rhizosphere microbiomes in European grassland. Soil Biology and. Biochemistry 138: 107604.

Beirinckx S, Viaene T, Haegeman A, Debode J, Amery F, Vandenabeele S. 2020. Tapping into the maize root microbiome to identify bacteria that promote growth under chilling conditions. Microbiome 8: 54.

Bulgarelli D, Rott M, Schlaeppi K, Ver Loren van Themaat E, Ahmadinejad N, Assenza F, Rauf P, Huettel B, Reinhardt R, Schmelzer E, Peplies J, Gloeckner FO, Amann R, Eickhorst T, Schulze-Lefert P. 2012. Revealing structure and assembly cues for Arabidopsis root-inhabiting bacterial microbiota. Nature 488: 91-95.

Cai ZQ, Wang XB, Sreetama B, Gao Q. 2020. Distinct factors drive the assembly of quinoaassociated microbiomes along elevation. Plant Soil 448: 55-69.

Carper DL, Carrell AA, Kueppers LM, Frank AC. 2018. Bacterial endophyte communities in Pinus flexilis are structured by host age, tissue type, and environmental factors. Plant Soil 
442

443

444

445

446

447

448

449

450

451

452

453

454

455

456

457

458

459

460

461

462

428: 335-352.

Carrell AA, Frank AC. 2015. Bacterial endophyte communities in the foliage of coast redwood and giant sequoia. Frontiers in Microbiology 6: 1008.

Carrión VJ, Perez-Jaramillo J, Cordovez V, Tracanna V, de Hollander M, Ruiz-Buck D, Mendes LW, Van IJcken W, Gomez-Exposito R, Elsayed SS, Mohanraju P, Arifah A, van der Oost J, Paulson JN, Mendes R, van Wezel GP, Medema MH, Raaijmakers JM. 2019. Pathogen-induced activation of disease-suppressive functions in the endophytic root microbiome. Science 366: 606-612.

Carvalhais LC, Dennis PG, Badri DV, Kidd BN, Vivanco JM, Schenk PM. 2015. Linking jasmonic acid signaling, root exudates, and rhizosphere microbiomes. Molecular PlantMicrobe Interactions 28: 1049-1058.

Chen P, Zhao M, Tang F, Hu Y, Peng X, Shen S. 2019. The effect of environment on the microbiome associated with the roots of a native woody plant under different climate types in China. Applied Microbiology and Biotechnology 103: 3899-3913.

Chen TH, Murata N. 2011. Glycinebetaine protects plants against abiotic stress: mechanisms and biotechnological applications. Plant Cell Environment 34: 1-20.

Chi F. 2006. Migration of rhizobia in plants and proteome analysis of their interaction. Beijing: Graduate School of Chinese Academy of Sciences. Doctor Disseration.

Chu Q, Zhang L, Zhou J, Yuan L, Chen F, Zhang F, Feng G, Rengel Z. 2020. Soil plantavailable phosphorus levels and maize genotypes determine the phosphorus acquisition efficiency and contribution of mycorrhizal pathway. Plant Soil 449:357-371 
463

464

465

466

467

468

469

470

471

472

473

474

475

476

477

478

479

480

481

482

483

Coleman-Derr D, Desgarennes D, Fonseca-Garcia C, Gross S, Clingenpeel S, Woyke T, North G, Visel A, Partida-Martinez LP, Tringe SG. 2016. Plant compartment and biogeography affect microbiome composition in cultivated and native Agave species. New Phytologist 209: 798-811.

Cordier T, Robin C, Capdevielle X, Fabreguettes O, Desprez-Loustau ML, Vacher C. 2012. The composition of phyllosphere fungal assemblages of European beech (Fagus sylvatica) varies significantly along an elevation gradient. New Phytolgist 196: 510-519.

Dini-Andreote F. 2020. Endophytes: the second layer of plant defense. Trends Plant Science 25: 319-322.

\section{Elkelish A, Qari SH, Mazrou YSA, Abdelaal KAA, Hafez YM, Abu-Elsaoud AM, Hafez} YM, Abu-Elsaoud AM, Batiha GE, El-Esawi MA, El Nahhas N. 2020. Exogenous ascorbic acid induced chilling tolerance in tomato plants through modulating metabolism, osmolytes, antioxidants, and transcriptional regulation of catalase and heat shock proteins. Plants 9: 431.

Farnese FS, Menezes-Silva PE, Gusman GS, Oliveira JA. 2016. When bad guys become good ones: The key role of reactive oxygen species and nitric oxide in the plant responses to abiotic stress. Frontiers in Plant Science 7: 471.

Fujimura KE, Egger KN, Henry GH. 2008. The effect of experimental warming on the rootassociated fungal community of Salix arctica. ISME J 2: 105-114.

Gomes E, Jakobsen MK, Axelsen KB, Geisler M, Palmgren MG. 2000. Chilling tolerance in Arabidopsis involves ALA1, a member of a new family of putative aminophospholipid 
translocases. Plant Cell 12: 2441-2453.

Hasegawa S, Meguro A, Shimizu M, Nishimura T, Kunoh H. 2006. Endophytic actinomycetes and their interactions with host plants. Actinomycetologica 20: 72-81.

Hiruma K, Gerlach N, Sacristán S, Nakano RT, Hacquard S, Kracher B, Neumann U, Ramírez D, Bucher M, O’Connell RJ, Schulze-Lefert P. 2016. Root endophyte Colletotrichum tofieldiae confers plant fitness benefits that are phosphate status dependent.

Horton MW, Bodenhausen N, Beilsmith K, Meng D, Muegge BD, Subramanian S, Vetter MM, Vilhjalmsson BJ, Nordborg M, Gordon JI, Bergelson, J. 2014. Genome-wide association study of Arabidopsis thaliana leaf microbial community. Nat Commun. 5:5320.

Jackrel SL, Schmidt KC, Cardinale BJ, Denef VJ. 2020. Microbiomes reduce their host's sensitivity to interspecific interactions. MBio. 11: e02657-19.

Jin CW, Zhao YG, Li XS, Zhi JJ, Zhang GL. 2017. Spatial distribution and environmental factors affecting mattic epipedon at different developmental levels in alpine meadows in the middle of Qilian Mountains. Acta Ecologica Sinica 37: 6732-6742.

Korner C. 2007. The use of "altitude" in ecological research. Trends Ecology and Evolution 22: 569-574.

Laforest-Lapointe I, Messier C, Kembel SW. 2016. Host species identity, site and time drive temperate tree phyllosphere bacterial community structure. Microbiome 4: 27.

Laforest-Lapointe I, Paquette A, Messier C, Kembel SW. 2017. Leaf bacterial diversity mediates plant diversity and ecosystem function relationships. Nature 546: 145-147. 
505

506

507

508

509

510

511

512

Langille MGI, Zaneveld J, Caporaso JG, McDonald D, Knights D, JA Reyes, Clemente JC, Burkepile DE, Vega Thurber RL, Knight R. 2013. Predictive functional profiling of microbial communities using 16S rRNA marker gene sequences. Nature Biotechnology 31: 814.

\section{Lebeis SL, Paredes SH, Lundberg DS, Breakfield N, Gehring J, McDonald M, Malfatti S,} del Rio D, Glavina T, Jones CD, Tringe SG. 2015. Salicylic acid modulates colonization of the root microbiome by specific bacterial taxa. Science 349: 860-864.

Li L, Yang A, Zhao Z. 2005. Seasonality of arbuscular mycorrhizal symbiosis and dark septate endophytes in a grassland site in southwest China. FEMS Microbiol Ecology 54: 367-373.

Li YQ, Wang XY, Niu YY, Lian J, Luo YQ, Chen YP. 2018. Spatial distribution of soil organic carbon in the ecologically fragile Horqin Grassland of northeastern China. Geoderma 325: 102-109.

Little CJ, Wheeler JA, Sedlacek J, Cortés AJ, Rixen C. 2016. Small-scale drivers: the importance of nutrient availability and snowmelt timing on performance of the alpine shrub Salix herbacea. Oecologia 180: 1015-1024.

Liu F, Zhang X, Cai B, Pan D, Fu X, Bi H, Ai X. 2020. Physiological response and transcription profiling analysis reveal the role of glutathione in $\mathrm{H}_{2} \mathrm{~S}$-induced chilling stress tolerance of cucumber seedlings. Plant Science 291: 110363.

Liu H, Brettell LE. 2019. Plant defense by VOC-induced microbial priming. Trends Plant Science 24: 187-189.

Liu H, Brettell LE, Qiu Z, Singh BK. 2020. Microbiome-mediated stress resistance in plants. 
Trends Plant Science. https://doi.org/10.1016/j.tplants.2020.03.014.

527 Liu H, Mi Z, Lin L, Wang Y, Zhang Z, Zhang F. 2018. Shifting plant species composition in 528 response to climate change stabilizes grassland primary production. PNAS 115: 4051-4056.

529 Lv XZ, Li HZ, Chen XX, Xiang X, Guo ZX, Yu JQ, Zhou YH. 2018. The role of calcium530 dependent protein kinase in hydrogen peroxide, nitric oxide and ABA-dependent cold

Ma ZY, Liu HY, Mi ZR, Zhang ZH, Wang YH, Xu W, Jiang L, He JS. 2017. Climate warming reduces the temporal stability of plant community biomass production. Nature Communications 8:15378.

Martín ML, Busconi L. 2001. A rice membrane_bound Calcium_dependent protein kinase is activated in response to low temperature. Plant Physiology. 125: 1442-1449.

Martinez-Garcia LB, De Deyn GB, Pugnaire FI, Kothamasi D, van der Heijden MGA. 2017. Symbiotic soil fungi enhance ecosystem resilience to climate change. Global Chang Biology 23: 5228-5236.

Meiser A, Bálint M, Schmitt I. 2014. Meta-analysis of deep-sequenced fungal communities indicates limited taxon sharing between studies and the presence of biogeographic patterns. New Phytologist 201: 623-635.

Miehe G, Mlehe S, Kaiser K, Liu JQ, Zhao XQ. 2008. Status and dynamics of Kobresia pygmaea ecosystem on the Tibetan plateau. Ambio. 37: 272-279.

Monroy AF, Sarhan F, Dhindsa RS. 1993. Cold_induced change in freezing tolerance, protein phosphorylation, and gene expression. Plant Physiology 102: 1127-1135. 
547 Morin X, Viner D, Chuine I. 2008. Tree species range shifts at a continental scale: new

548 predictive insights from a process-based model. Journal of Ecology 96:784-794

549 Moyes AB, Castanha C, Germino MJ, Kueppers LM. 2013. Warming and the dependence of

550 limber pine (Pinus flexilis) establishment on summer soil moisture within and above its

$551 \quad$ current elevation range. Oecologia 171: 271-282.

552

553

554

555

556

557

558

559

560

561

562

563

564

565

566

567

Neal AL, Ahmad S, Gordon-Weeks R, Ton J. 2012. Benzoxazinoids in root exudates of maize attract Pseudomonas putida to the rhizosphere. PLoS One 7: e35498.

Niu Y, Yang S, Zhou J, Chu B, Ma S, Zhu H. 2019. Vegetation distribution along mountain environmental gradient predicts shifts in plant community response to climate change in alpine meadow on the Tibetan Plateau. Science of Total Environment. 650: 505-514.

Odelade KA, Babalola OO. 2019. Bacteria, fungi and archaea domains in rhizospheric soil and their effects in enhancing agricultural productivity. International Journal of Environmental Research and Public Health 16: 3873.

Porras-Alfaro A, Bayman P. 2011. Hidden fungi, emergent properties: endophytes and microbiomes. Annual Review of Phytopathology 49: 291-315.

Qi J, Liu WH, Jiao T, Hamblin A. 2020. Variation in morphological and physiological characteristics of wild Elymus nutans ecotypes from different altitudes in the northeastern Tibetan Plateau. Journal of Sensors 11: 1-11.

Qian X, Chen L, Guo XM, He D, Shi MM, Zhang DX. 2018. Shifts in community composition and co-occurrence patterns of phyllosphere fungi inhabiting Mussaenda shikokiana along an elevation gradient. Peer J 6: e5767. 
568

569

570

571

572

Qian X, Li HZ, Wang YL, Wu BW, Wu MS, Chen L, Qian X. 2019. Leaf and root endospheres harbor lower fungal diversity and less complex fungal co-occurrence patterns than rhizosphere. Frontiers in Microbiology 10: 15.

Reinhardt K, Castanha C, Germino MJ, Kueppers LM. 2011. Ecophysiological variation in two provenances of Pinus flexilis seedlings across an elevation gradient from forest to alpine. Tree Physiology 31: 615-625.

Rubin RL, Jones AN, Hayer M, Shuman-Goodier ME, Andrews LV, Hungate BA. 2020. Opposing effects of bacterial endophytes on biomass allocation of a wild donor and agricultural recipient. FEMS Microbiology Ecology. doi:10.1093/femsec/fiaa012.

Santoyo G, Moreno-Hagelsieb G, Orozco-Mosqueda MC, Glick BR. 2016. Plant growthpromoting bacterial endophytes. Microbiological Research 183: 92-99.

Schulz B, Boyle C. 2005. The endophytic continuum. Mycological Research 109: 661-686.

Shi Y, Phan H, Liu Y, Cao S, Zhang Z, Chu C, Schläppi MR. 2020. Glycosyltransferase OsUGT90A1 helps protect the plasma membrane during chilling stress in rice. Journal of Experimental Botany 71: 2723-2739.

Taghavi S, Garafola C, Monchy S, Newman L, Hoffman A., Weyens N, Barac T, Vangronsveld J, van der Lelie D. 2009. Genome survey and characterization of endophytic bacteria exhibiting a beneficial effect on growth and development of poplar trees. Applied Environmental Microbiology 75: 748-757.

Tiryaki D, Aydin I, Atici O. 2019. Psychrotolerant bacteria isolated from the leaf apoplast of cold-adapted wild plants improve the cold resistance of bean (Phaseolus vulgaris L.) under 
589

590

591

592

593

594

595

596

597

598

599

600

601

602

603

604

605

606

607

608

609

low temperature. Cryobiology 86: 111-119.

Toju H, Kurokawa H, Kenta T. 2019. Factors influencing leaf and root-associated communities of bacteria and fungi across 33 plant orders in a grassland. Front Microbiol 10. DOI: $10.3389 /$ fmicb.2019.00241

van der Heijden MGA, de Bruin S, Luckerhoff L, van Logtestijn RSP, Schlaeppi K. 2016. A widespread plant-fungal-bacterial symbiosis promotes plant biodiversity, plant nutrition and seedling recruitment. ISME J 10: 389-399.

Wang F, Men X, Zhang G, Liang K, Xin Y, Wang J, Li A, Zhang H, Liu H, Wu L. 2018. Assessment of 16S rRNA gene primers for studying bacterial community structure and function of aging flue-cured tobaccos. AMB Express 8: 182.

Wang Q, Zhang ZH, Du R, Wang SP, Duan JC, Iler AM. 2019. Richness of plant communities plays a larger role than climate in determining responses of species richness to climate change. Journal of Ecology 107: 1944-1955.

Wallace J, Laforest-Lapointe I, Kembel SW. 2018. Variation in the leaf and root microbiome of sugar maple (Acer saccharum) at an elevational range limit. Peer J 6: e5293.

Wu L, Wang M, OUYANG H, Cheng SK, Song MH. 2017. Spatial distribution modelling of Kobresia pygmaea (Cyperaceae) on the Qinghai--Tibetan Plateau. Journal of Resource Ecology 8:20-29.

Yan YL, Yang J, Dou Y, Chen M, Ping SZ, Peng JP, Lu W, Zhang WP, Yan ZY, Li HQ, Liu W, He S, Geng LZ, Zhang XB, Yang F, Yu HY, Zhan YH, Li DH, Lin ZL, Wang YP, EImerich C, Lin M, Jin Q. 2008. Nitrogen fixation island and rhizosphere competence 
traits in the genome of root-associated Pseudomonas stutzeriA1501. PNAS 105: 7564-7569.

611

612

613

614

615

616

617

618

619

620

621

622

623

624

625

626

627

628

Yanni YG, Rizk YR, Abd El-Fattah FK, Squartini A, Corich V, Giacomini A, de Bruijn F, Rademaker J, Maya-Flores J, Ostrom P, Vega-Hernande M, Hollingsworth RI, Martinez-Molina E, Mateos P, Velazquez E, Wopereis J, Triplett E, Umali-Garcia M, Anarna JA, Rolfe BG, Ladha JK, Hill J, Mujoo R, Ng PK, Dazzo FB. 2001. Beneficial Plant Growth-Promoting Association of Rhizobium leguminosarum bv. trifolii with Rice Roots. Australian journal of plant physiology 28: 845-870.

Yao H, Sun X, He C, Maitra P, Li XC, Guo LD. 2019. Phyllosphere epiphytic and endophytic fungal community and network structures differ in a tropical mangrove ecosystem. Microbiome 7: 57.

Zarraonaindia I, Owens SM, Weisenhorn P, West K, Hampton-Marcell J, Lax S, Bokulich NA, Mills DA, Martin G, Taghavi S. 2015. The soil microbiome influences grapevineassociated microbiota. MBio 6: e02527-14.

Zhang L, Zhang W, Li Q, Cui R, Wang Z, Wang Y, Zhang YZ, Ding W, Shen XH. 2020. Deciphering the root endosphere microbiome of the desert plant Alhagi sparsifolia for drought resistance-promoting bacteria. Applied and Environmental Microbiology 86: e02863-19.

Zilber-Rosenberg I, Rosenberg E. 2008. Role of microorganisms in the evolution of animals and plants: the hologenome theory of evolution. FEMS Microbiol Reviews 32: 723-735. 


\section{Table $\mathbf{1}$ (on next page)}

Table 1. Significance test of community composition differences among elevations and hosts determined by permutational multivariate analysis of variance using distance matrices (PERMANOVA) according to Bray-Curtis distances. 
1 Table 1. Significance test of community composition differences among elevations and hosts

2 determined by permutational multivariate analysis of variance using distance matrices

3 (PERMANOVA) according to Bray-Curtis distances.

4

\begin{tabular}{llllll}
\hline \multirow{2}{*}{ Bacteria } & & & \multicolumn{2}{l}{ Anosim } \\
& \multirow{2}{*}{ Elevation } & E. nutans & $R$ & $P$ \\
\cline { 3 - 5 } & & K. pygmaea & 0.416 & 0.001 \\
& Host species & E. nutans vs K. pygmaea & 0.78 & 0.001 \\
\hline \multirow{3}{*}{ Fungi } & Elevation & E. nutans & 0.756 & 0.001 \\
& & K. pygmaea & 0.984 & 0.001 \\
& & Host species & E. nutans vs K. pygmaea & 0.579 & 0.001 \\
\hline
\end{tabular}

5

6

7

8

9

10

11

12

13

14 


\section{Table 2 (on next page)}

Spearman correlation analysis between elevation and the relative abundance of bacterial and fungal at genus level. 
1 Table 2. Spearman correlation analysis between elevation and the relative abundance of bacterial

2 and fungal at genus level.

\begin{tabular}{|c|c|c|c|c|c|}
\hline & \multirow{2}{*}{ Genus } & \multicolumn{2}{|c|}{ K. pygmaea } & \multicolumn{2}{|c|}{ E. nutans } \\
\hline & & $R$ & $P$ & $R$ & $P$ \\
\hline \multirow[t]{9}{*}{ Bacteria } & Pseudomonas & 0.731 & 0.002 & 0.153 & 0.587 \\
\hline & Pantoea & 0.633 & 0.011 & 0.556 & 0.031 \\
\hline & Rhizobium & -0.546 & 0.035 & 0.011 & 0.969 \\
\hline & Acidibacter & -0.676 & 0.006 & -0.207 & 0.458 \\
\hline & Actinophytocola & -0.524 & 0.045 & 0.022 & 0.938 \\
\hline & Cryptosporangium & -0.676 & 0.006 & -0.016 & 0.954 \\
\hline & Serratia & 0.535 & 0.040 & 0.491 & 0.063 \\
\hline & Sphingomonas & -0.262 & 0.346 & 0.644 & 0.010 \\
\hline & Paenibacillus & 0.742 & 0.002 & 0.764 & 0.001 \\
\hline \multirow[t]{6}{*}{ Fungi } & Mycena & 1.000 & 0.000 & -0.700 & 0.188 \\
\hline & Mortierella & 0.900 & $\mathbf{0 . 0 3 7}$ & -0.900 & $\mathbf{0 . 0 3 7}$ \\
\hline & Cistella & 0.700 & 0.188 & -0.900 & $\mathbf{0 . 0 3 7}$ \\
\hline & Ilyonectria & 0.900 & $\mathbf{0 . 0 3 7}$ & -0.800 & 0.104 \\
\hline & Sebacina & 0.900 & $\mathbf{0 . 0 3 7}$ & -0.700 & 0.188 \\
\hline & Leptosphaeria & 0.975 & 0.005 & -0.616 & 0.269 \\
\hline
\end{tabular}

3 
Figure 1

Shannon index of root endophytic bacteria (A) and fungi (B) in K. pygmaea and $E$. nutans at different elevations.

Averages \pm SE are displayed $(n=3)$. Different letters indicate significant differences between elevations 

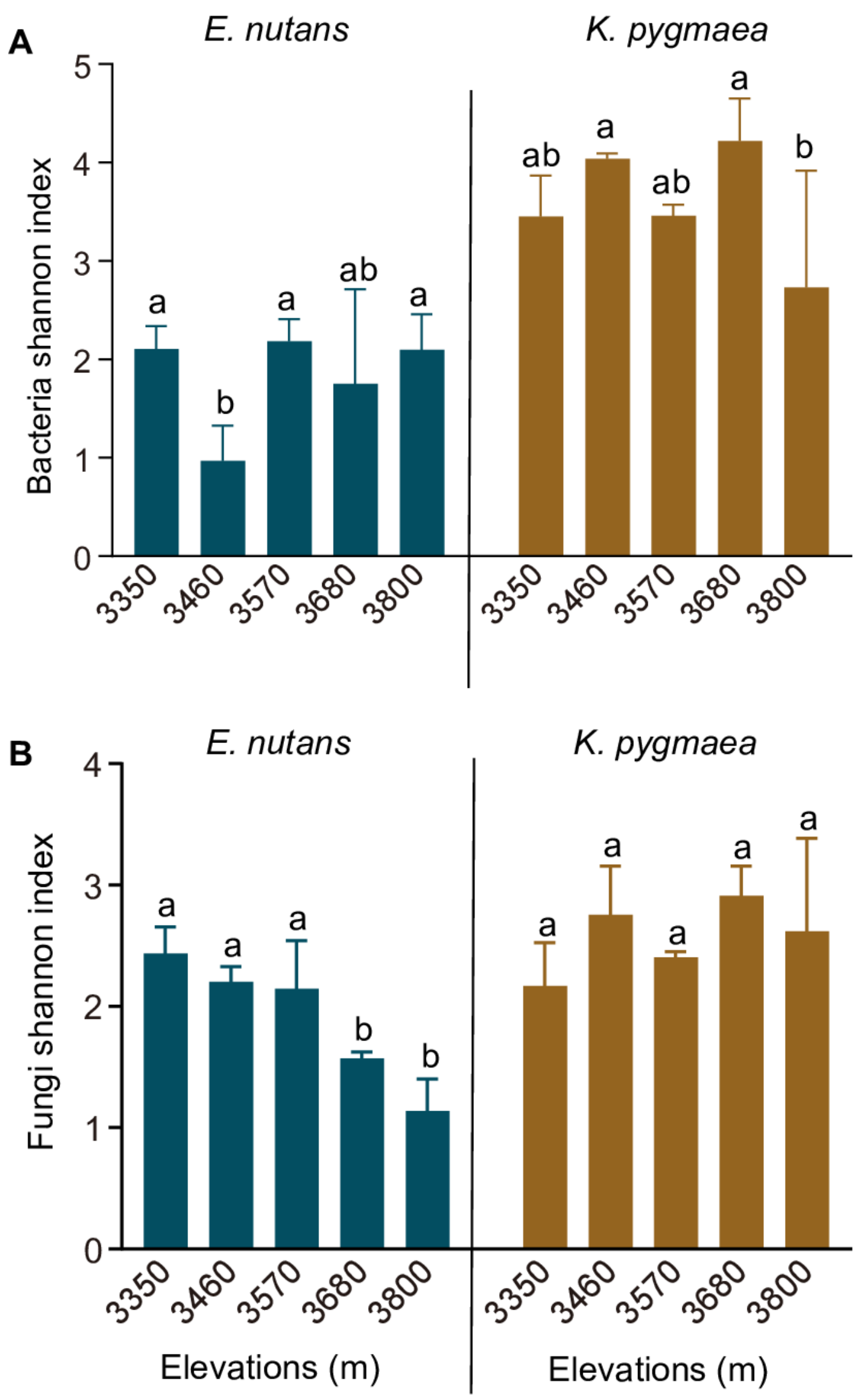


\section{Figure 2}

Non-metric multidimensional scaling (NMDS) ordination of the community composition of endophytic bacteria and fungi based on Bray-Curtis distances.

$A$ and $B$ indicated fungal and bacterial community composition in $E$. nutans and $K$. pygmaea root regardless of elevations; $C$ and $D$ indicated fungal and bacterial community composition at different elevations in $E$. nutans root; $E$ and $F$ indicated fungal and bacterial community composition at different elevations in $K$. pygmaea root. Plant species were distinguished by colors, and elevations were distinguished by shapes. 

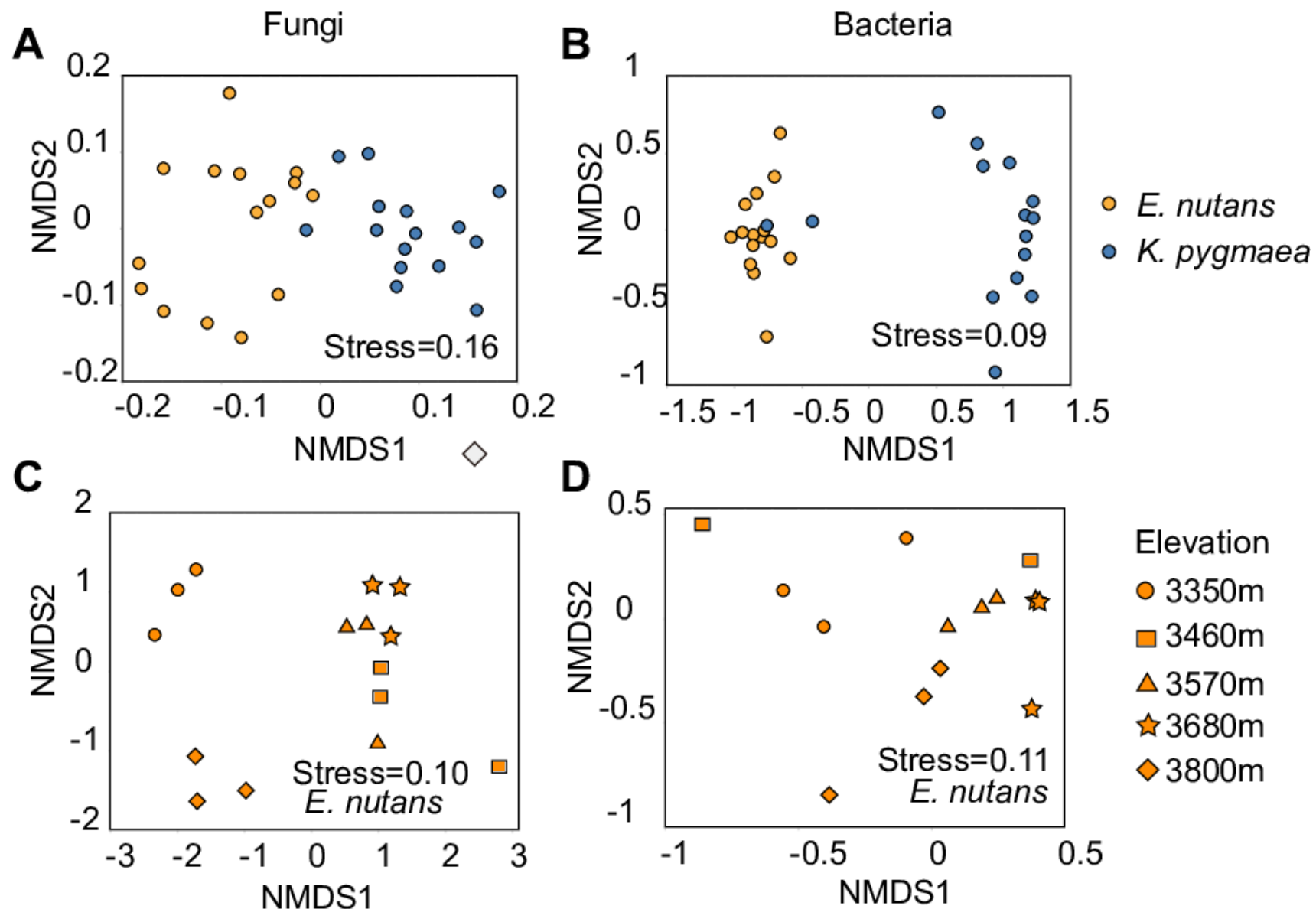

Elevation - $3350 \mathrm{~m}$ $\square 3460 \mathrm{~m}$ $\triangle 3570 \mathrm{~m}$ 的 $3680 \mathrm{~m}$ $\diamond 3800 \mathrm{~m}$

E

F
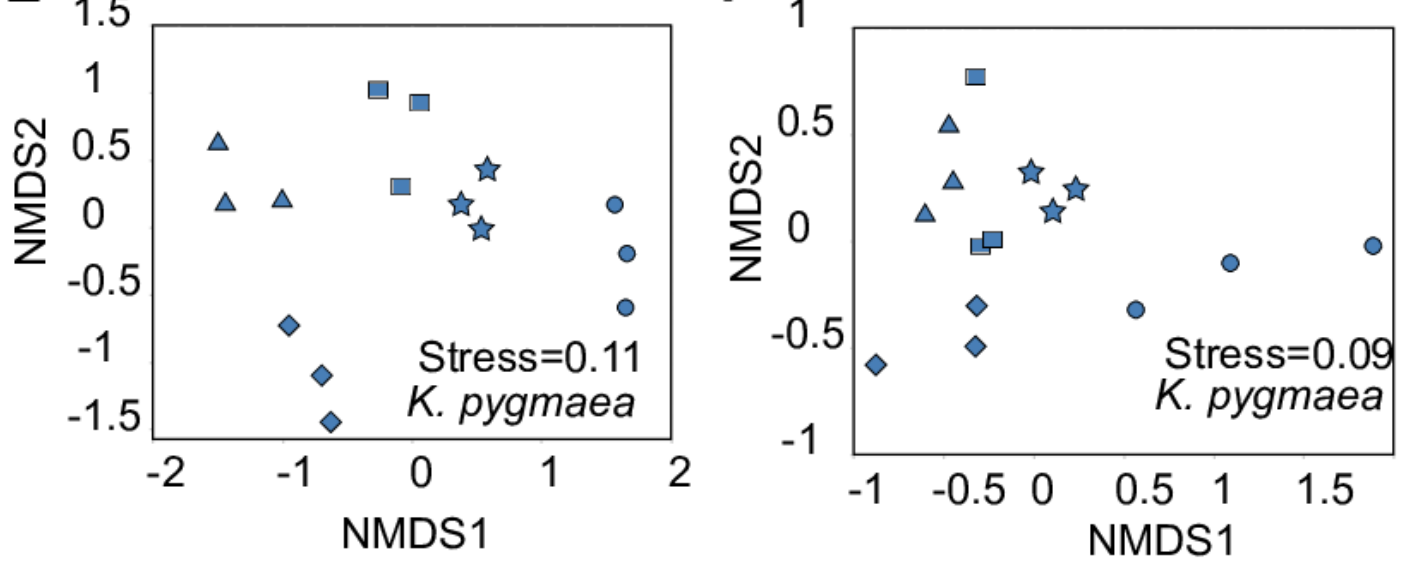

Elevation - $3350 \mathrm{~m}$ - $3460 \mathrm{~m}$ $\triangle 3570 \mathrm{~m}$ $3680 \mathrm{~m}$ $\diamond 3800 \mathrm{~m}$ 
Figure 3

Relative abundance of bacterial (a) and fungal taxa (b) at the order level.

ER E. nutans root; KR K. pygmaea root; the numbers represent elevations. For example, ER3350 indicate $E$. nutans root at the elevation of 3350 m; KR3350 indicate $K$. pygmaea root at the elevation of $3350 \mathrm{~m}$. The same as below. 
A

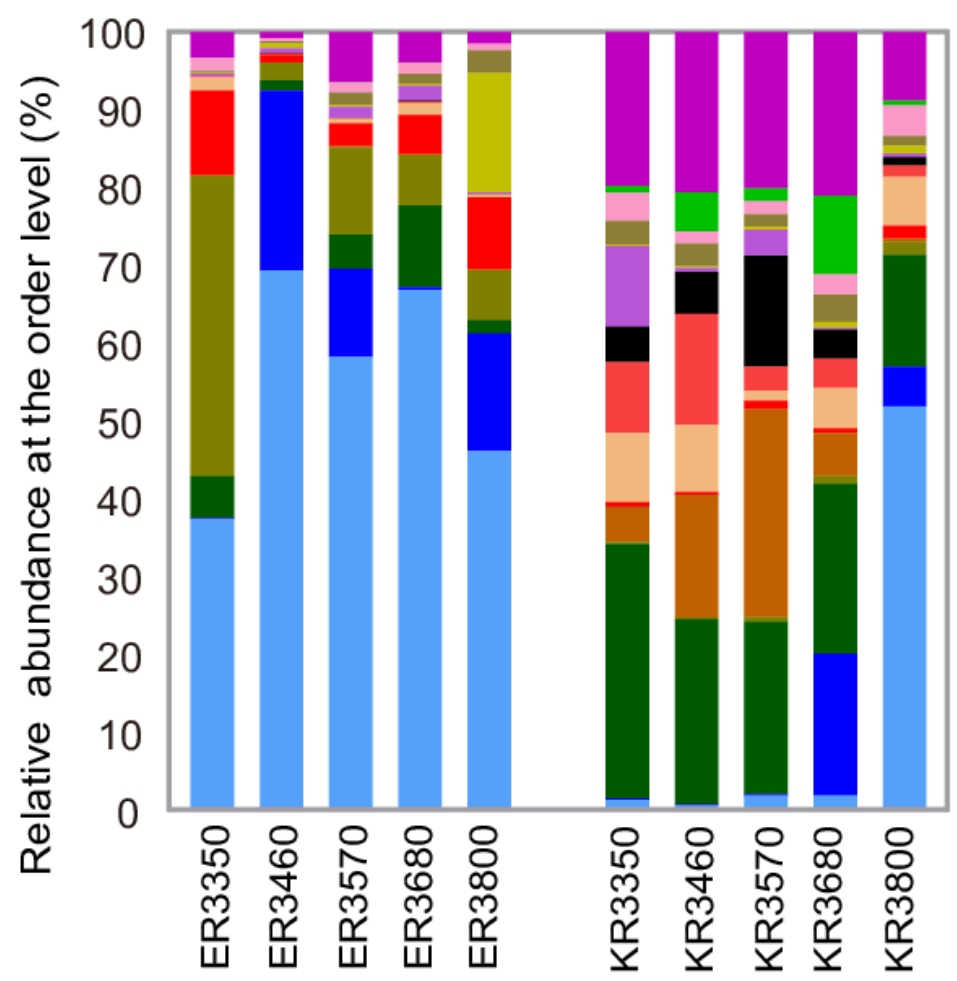

- others

- Solirubrobacterales

- Caulobacterales

- Sphingomonadales

- Bacillales

- Xanthomonadales

- Micromonosporales

Gammaproteobacteria

- Incertae_Sedis

- Chitinophagales

- Betaproteobacteriales

- Mollicutes_Incertae_Sedis

- Pseudonocardiales

- Flavobacteriales

- Rhizobiales

- Enterobacteriales

- Pseudomonadales

B

Fungi

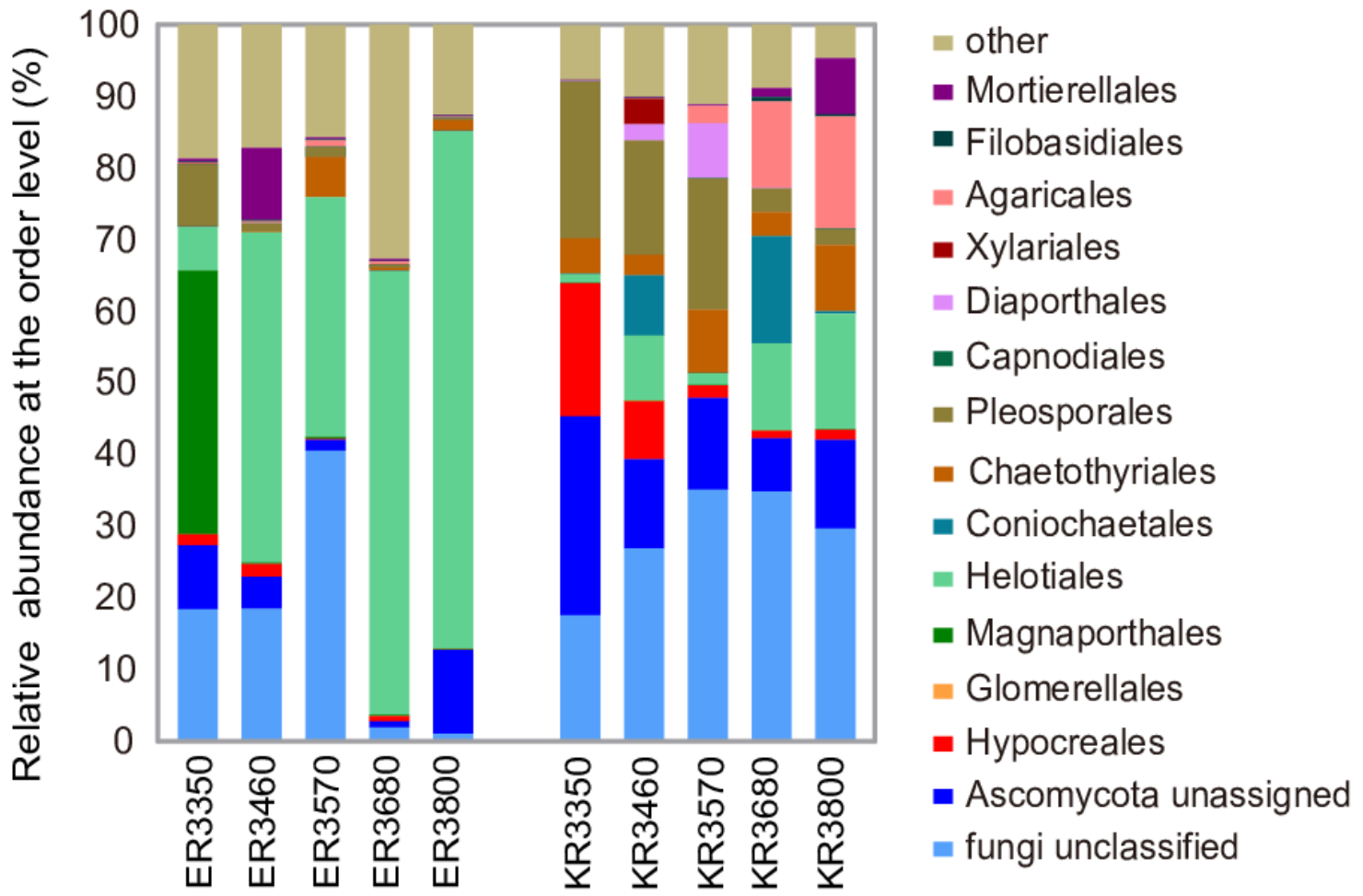




\section{Figure 4}

Cladograms of LEfSe showing bacterial and fungal taxa with significant differences in relative abundance between $K$. pygmaea and $E$. nutans.

The filled circles from inside to outside indicate the taxonomic levels with phylum, class, order, family, genus, and species. Circles or nodes shown in color corresponding to different plant species represented a significantly more abundant group. Yellow circles indicate species with no significant differences in relative abundance. 


\section{Bacteria}

A

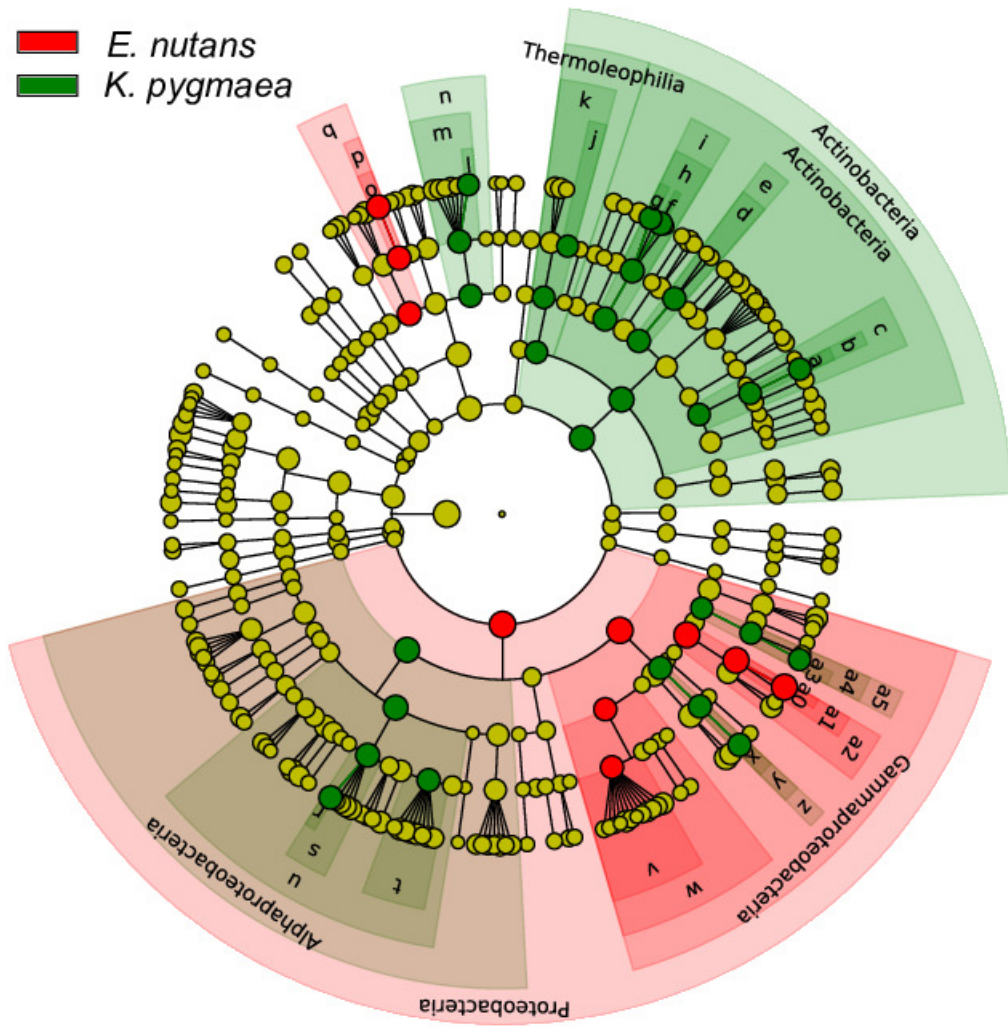

Fungi

B

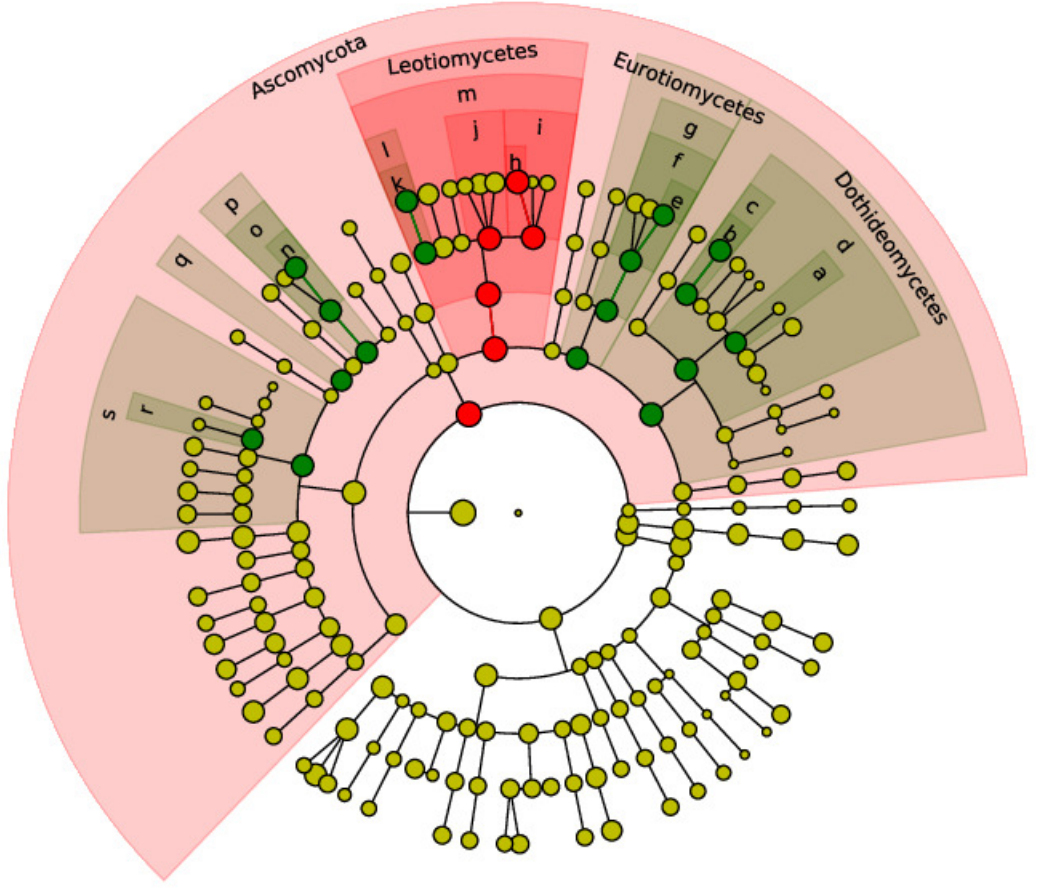

a: Cryptosporangium

b: Cryptosporangiaceae

c: Frankiales

d: Micromonosporaceae

e: Micromonosporales

f: Actinophytocola

g: Pseudonocardia

h: Pseudonocardiaceae

i: Pseudonocardiales

j: 67 14

k: Solirubrobacterales

I: Chitinophaga

m: Chitinophagaceae

n: Chitinophagales

o: Flavobacterium

p: Flavobacteriaceae

q: Flavobacteriales

r: Allorhizobium_Neorhizobiu।

s: Rhizobiaceae

t: Xanthobacteraceae

u: Rhizobiales

v: Burkholderiaceae

w: Betaproteobacteriales

x: Acidibacter

y: Unknown_Family

z: Gammaproteobacteria_Inc

a0: Pseudomonas

al: Pseudomonadaceae

$\square$ a2: Pseudomonadales

a3: Steroidobacter

a4: Steroidobacteraceae

a5: Steroidobacterales

a: Massarinaceae
b: unidentified
c: unidentified
d: Pleosporales
e: Cladophialophora
f: Herpotrichiellaceae
g: Chaetothyriales
h: unidentified
i: Helotiaceae
j: Hyaloscyphaceae
k: unidentified
i: unidentified
m: Helotiales
n: Coniochaeta
o: Coniochaetaceae
p: Coniochaetales
q: Diaporthales
r: Hypocreales_fam_Incertae.
s: Hypocreales


Figure 5

Differences in relative abundance of functional genes associated with cold resistance, nitrogen absorption, phosphatase and antioxidase between $K$. pygmaea and $E$. nutans.

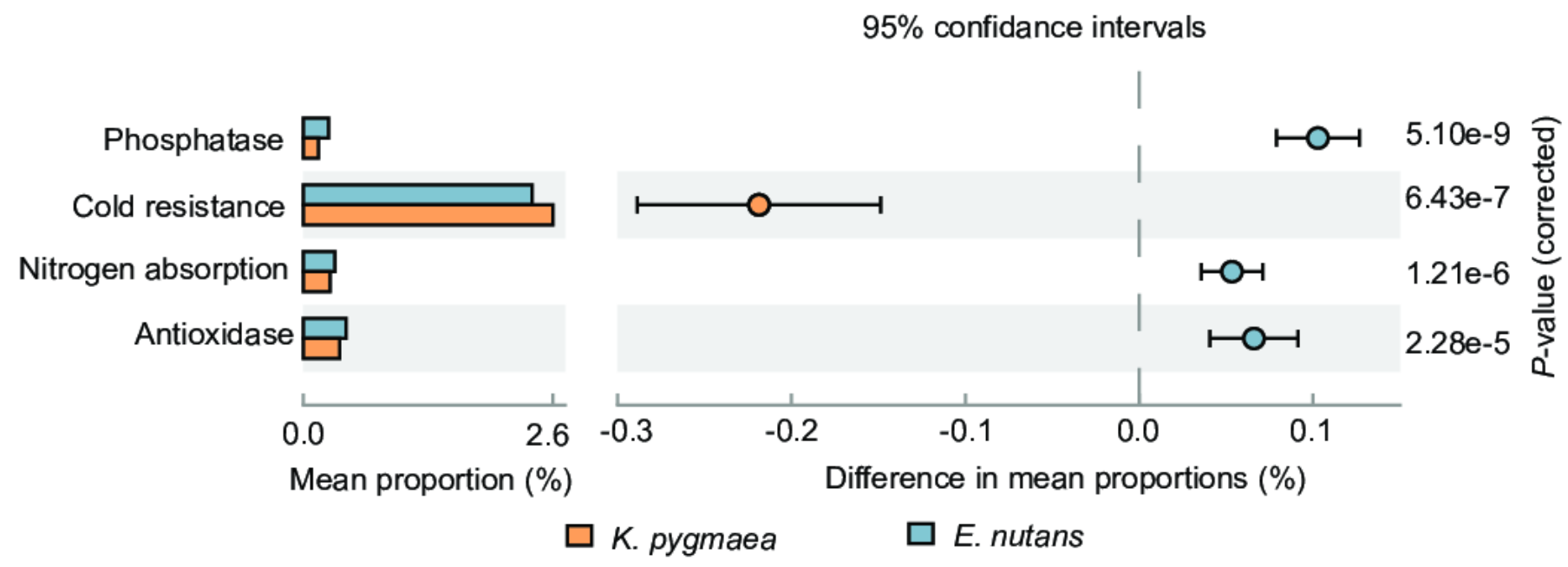




\section{Figure 6}

Frame diagram of response of endophytic bacterial and fungal community to altitude

The proportion of Elymus nutans in vegetation community as well as its endophytic fungal diversity decreased with elevation increasing. While, the proportion of Kobresia pygmaea as well as its endophytic fungal diversity showed a slight increase trend with elevation increasing. The Shannon index of root bacterial and fungal community in Kobresia pygmaea were higher than that in Elymus nutans. Besides, bacteria in Kobresia pygmaea root had more genes associated with cold resistance, and in Elymus nutans root had more genes associated with nutrient absorption. 


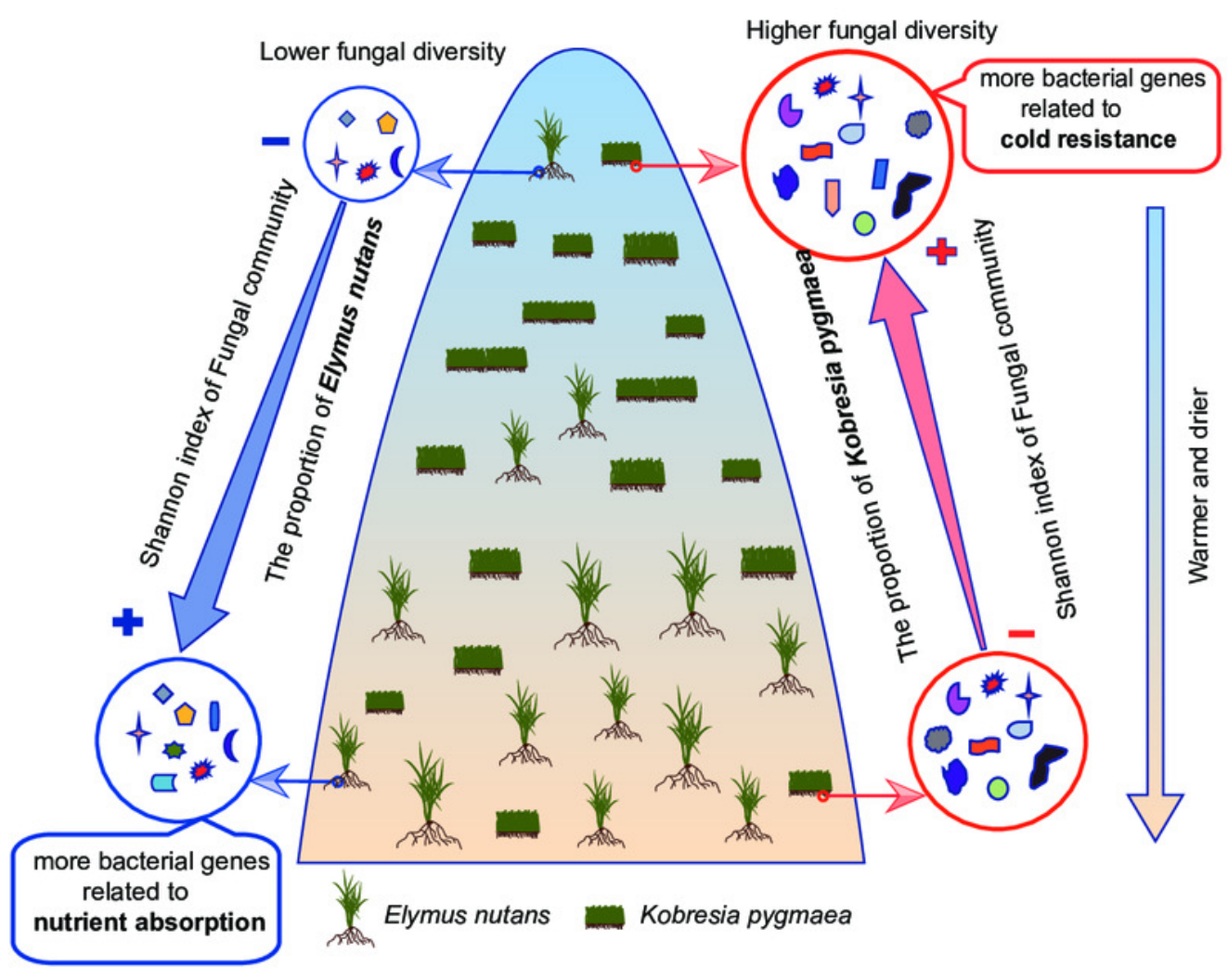

